\title{
INCIDENCE OF DIARRHEA BY Clostridium difficile IN HEMATOLOGIC PATIENTS AND HEMATOPOIETIC STEM CELL TRANSPLANTATION PATIENTS: RISK FACTORS FOR SEVERE FORMS AND DEATH
}

\author{
Fernanda SPADÃO(1), Juliana GERHARDT(1), Thais GUIMARÃES(1), Frederico DULLEY(2), João Nóbrega de ALMEIDA JUNIOR(3), \\ Marjorie Vieira BATISTA(4), Maria Aparecida SHIKANAI-YASUDA(4), Anna Sara LEVIN(4) \& Silvia Figueiredo COSTA(4)
}

\begin{abstract}
SUMMARY
We describe the rate of incidence of Clostridium difficile-associated diarrhea (CDAD) in hematologic and patients undergone stem cell transplant (HSCT) at HC-FMUSP, from January 2007 to June 2011, using two denominators 1,000 patient and 1,000 days of neutropenia and the risk factors associated with the severe form of the disease and death. The ELISA method (Ridascreen-Biopharm, Germany) for the detections of toxins A/B was used to identify $C$. difficile. A multivariate analysis was performed to evaluate potential factors associated with severe CDAD and death within 14 days after the diagnosis of CDAD, using multiple logistic regression. Sixtysix episodes were identified in 64 patients among 439 patients with diarrhea during the study period. CDA rate of incidence varied from 0.78 to 5.45 per 1,000 days of neutropenia and from 0.65 to 5.45 per 1,000 patient-days. The most common underlying disease was acute myeloid leukemia 30/64 (44\%), 32/64 (46\%) patients were neutropenic, 31/64 (45\%) undergone allogeneic HSCT, 61/64 $(88 \%)$ had previously used antibiotics and 9/64 (13\%) have severe CDAD. Most of the patients (89\%) received treatment with oral metronidazole and 19/64 (26\%) died. The independent risk factors associated with death were the severe form of CDAD, and use of linezolid.
\end{abstract}

KEYWORDS: Hematology; Bone marrow transplant; C. difficile.

\section{INTRODUCTION}

Diarrhea is a common complication in patients who receive high doses of chemotherapy and in those undergone hematopoietic stem cell transplant (HSCT) $)^{3,13,21,23}$. Clostridium difficile has frequently been identified as cause of infectious diarrhea in hospital setting. Its incidence rates range from $4.8 \%$ to $9 \%$ in patients with acute myelogenous leukemia, from $4.9 \%$ to $7.5 \%$ in patients undergoing autologous and from $14 \%$ to $30.4 \%$ in those undergoing allogeneic $\mathrm{HSCT}^{1,2,4,16,25}$. The frequent and prolonged use of antibiotics may increase even further the risk of C. difficile associated diarrhea (CDAD) in this population of patients ${ }^{23}$. Despite these risk factors being frequent in these patients, data of CDAD in haematologic patients are still scarce.

Therefore, studies that evaluate CDAD in this population of patients can be useful for delineating measures of control and prevention of dissemination of this agent.

\section{OBJECTIVE}

To describe the rate of incidence and treatment of CDAD in hematological and HSCT patients, and the risk factors associated with the severe form of the CDAD and death.

\section{PATIENTS, MATERIAL, METHODS}

Study setting: The hematology and bone marrow transplant wards have 20 beds, are located in the Central Institute of Hospital das Clinicas (ICHC-FMUSP), Brazil, a teaching hospital with 1,000 beds. The bone marrow ward has four rooms, totalizing eight beds, and one room for contact isolation. All suspected cases of CDAD were placed in a contact isolation room, and remained in isolation until resolution of symptoms.

Study design: It is a retrospective study, the clinical records of all the patients in the hematology and bone marrow transplant wards during the period from January 2007 to June 2011 that performed C. difficile toxins $\mathrm{A} / \mathrm{B}$ were analyzed. Its study has been approved by the Hospital das Clinicas of University of São Paulo, Brazil, Ethics Committee.

Definition of a case of CDAD: Hematologic patient with diarrhea (three or more soft stools within 24 hours) and positive for toxins A/B, who received treatment for CDAD.

(1) Nosocomial Infection Control Team of Hospital das Clinicas of University of São Paulo, São Paulo, SP, Brazil.

(2) Bone Marrow Transplant Unit, Hospital das Clinicas of University of São Paulo, São Paulo, SP, Brazil.

(3) Laboratory of Microbiology of Hospital das Clinicas of University of São Paulo, São Paulo, SP, Brazil

(4) Infectious Diseases Department of Unversity of São Paulo, Brazil.

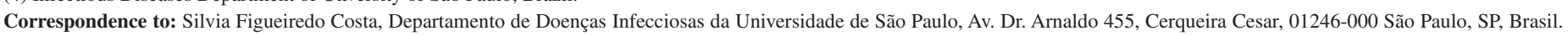
Fax: +55.11.30617043. E-mail: costasilviaf@ig.com.br 


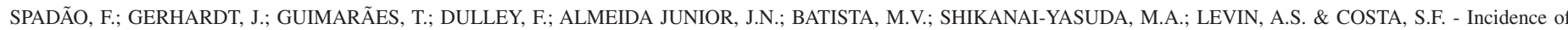
diarrhea by Clostridium difficile in hematologic patients and hematopoietic stem cell transplantation patients: risk factors for severe forms and death. Rev. Inst. Med. Trop. Sao Paulo, 56(4): 325-31, 2014.

Patients considered suspect were those who presented diarrhea and collected stools for the investigation of $C$. difficile toxins A/B.

Definition of severe disease: Patients presented with one or more of the following variables during the treatment of diarrhea: hypotension; shock, renal insufficiency ( $50 \%$ decreases in creatinine clearance), toxic megacolon; colectomy and death within up to 30 days of onset of clinical symptoms.

The incidence rates of CDAD were calculated using two denominators: 1,000 patient-days and 1,000 days of neutropenia.

Data collection: Data on the number of hematologic and HSCT patients who sent stool samples for toxins $A / B$ investigation were provided by the Information and Hospital Management System (SIGH) of the Central Laboratory Department (DLC). Data with positive toxins $\mathrm{A} / \mathrm{B}$ are stored in a database of the sub-commission of hospital infection control of the Central Institute of Hospital das Clinicas of University of São Paulo.

The following variables were evaluated: age, gender, underlying disease, type of autologous and allogeneic HSCT (related or unrelated), time of transplant until the onset of diarrhea, presence of neutropenia, neutropenia/day, mucositis (presence and degree of mucositis as per the WHO), graft versus host disease (GVHD), the antimicrobials used; immunosuppressant drugs and chemotherapy, prior use of an antibiotic (up until 30 days before the development of diarrhea), and if the patients stayed in the same room. Other causes of diarrhea (rotavirus, parasites, GVHD, or neutropenic colitis), reactivation of cytomegalovirus (PCR and/ or antigenemia positive in the blood), Vancomycin-Resistant Enterococci (VRE) colonization, performance of colonoscopy, and presence of pseudomembrane. The surveillance culture for identification of (VRE) is carried out weekly by rectal swab and/or stool culture and seeded in a selective medium with $6 \mu \mathrm{g} / \mathrm{mL}$ of vancomycin from all patients in the hematology and bone marrow transplant wards. Antigenemia and real-time polymerase chain reaction for Cytomegalovirus are performed twice a week in all HSCT patients from the moment of marrow infusion to one hundred days after transplantation.

The room and period of inpatient stay of the patients were evaluated to verify how many patients were contacts of a positive case of $C$. difficile, and how many developed CDAD.

The following data relative to the treatment of CDAD were evaluated: type of antibiotic used (oral/venous metronidazole or vancomycin), dosage, time, change in clinical picture. Clinical response in seven days: symptom resolution; partial response (50\% reduction in frequency of diarrhea episodes); no response; worsening (megacolon and/or perforation). Response at the end of treatment (last day of antibiotic specific for the treatment of CDAD) was evaluated: symptom resolution; partial response (50\% reduction in the frequency of diarrhea episodes); no response; worsening; and if there is relapse within 30 days.

Deaths during the treatment of CDAD were evaluated, considering death until 14 days after the onset of treatment, and death during hospitalization.

Microbiological procedures: The ELISA method (Ridascreen-
Biopharm, Germany) was used to identify C. difficile toxins A/B.

Statistical analysis: The information was filed in a computerized database utilizing the Epi Info 6.04b program. A descriptive analysis was made of patient characteristics; continuous variables were expressed as mean, standard deviation, median, and interval, and compared by Wilcoxon's test, and the categorical variables by Chi-squared and Fisher's Exact tests. The outcomes studied were severity of the clinical symptoms and death within 14 days after the diagnosis of CDAD. The level of significance adopted for comparison of the variables in the bivariate was the value of $p<0.05$. A multivariate analysis was performed to evaluate potential factors associated with severe CDAD and death within 14 days after the diagnosis of CDAD, using multiple logistic regression. The variables with $p<0.10$ in the bivariate analysis and biological plausibility were tested in the multivariate analysis by stepwise forward. Chi-squared for tendency was used to evaluate the distribution of suspected and confirmed cases of CDAD and the incidence of cases confirmed during the study period from 2007 to 2011.

\section{RESULTS}

During the study period (January 2007 to June 2011), 983 hematology and 1136 HSCT inpatients were followed, a total of 25,312 patients-day and 9,902 days of neutropenia. Four hundred thirty-nine patients with diarrhea performed $C$. difficile toxins A/B tests. A total of 66 episodes of CDAD in 64 patients were positive and the records of these patients were reviewed. During the study period the cumulative incidence of CDAD was $3.1 \%$. The rate of incidence of CDAD per 1,000 days of neutropenia varied from 0.78 to 5.45 and per 1,000 patient-days varied from 0.78 to 10.24 during the study period. The Chi-squared for tendency showed that the number of suspected cases of CDAD $(p=0.4180)$ and severe form of diseases $(p=0.69)$ remained stable, in contrast with the increase in number of confirmed cases $(p=0.0006)$.

The clinical and demographic data of 64 patients with CDAD over the study period are shown on Table 1 . Most $(68 \%)$ of the patients were males, the age varied from 12 to 65 years old, and the mean age was 38.9; median 38.5 and mode 38.0 years old. The most common underlying disease was acute myeloid leukemia 30/64 (44\%), and of these, 32/64 (46\%) were neutropenic, 31/64 (45\%) undergone allogeneic HSCT, and $61 / 64(88 \%)$ of the patients had received antibiotics. $C$. difficile-associated diarrhea was more frequent in HSCT patients 46/64 (69\%), of which $31 / 46(67 \%)$ were allogeneic transplants, than in hematologic patients $18 / 64(31 \%)$. The overall mortality was $24 / 64(35 \%)$ and the mortality within 14 days of diagnosis was 19/64 (26\%).

At the onset of diarrhea, the use of metronidazole was introduced after collecting the stool before the result of test for CDAD. The average number of days to perform the toxins test until the use of metronidazole was one day. Most (89\%) of the patients were treated with metronidazole; four patients initiated oral treatment and then switched to intravenous; three patients were hospitalized in ICU and received metronidazole intravenously. After seven days of treatment with metronidazole, 37\% of the patients showed a partial response, and $57 \%$ had symptoms resolution with 14 days of treatment. Three patients experienced relapse of the disease in less than 30 days. Of the $43 \%$ that did not show symptom resolution at the end of treatment (14 days), 24\% died during hospitalization, $3 \%$ had coinfection, and $3 \%$ GVHD. The severe form of 


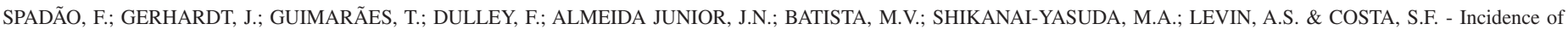
diarrhea by Clostridium difficile in hematologic patients and hematopoietic stem cell transplantation patients: risk factors for severe forms and death. Rev. Inst. Med. Trop. Sao Paulo, 56(4): 325-31, 2014

Table 1

Demographic and clinical data of hematologic and HSCT patients with diarrhea due to $C$. difficile, HC-FMUSP, 2007 to June 2011

\begin{tabular}{lcc}
\hline & N: 64 patients & $\%$ \\
\hline Age & Mean age 38.5 & \\
& $(12-65$ years old $)$ & \\
\hline
\end{tabular}

\section{Underlying Disease}

Aplasia

Acute Lymphoid Leukemia

Acute Myeloid Leukemia

Chronic Myeloid Leukemia

Lymphoma

Multiple Myeloma

Others

Hospitalization Unit

Hematology

Bone Marrow

Type of HSCT

Allogeneic

Unrelated

Autologous

Days after HSCT until diarrhea

Days of hospitalization until diarrhea

Days of neutropenia until diarrhea

Prior use of antibiotic

Sulfamethoxazole+trimethoprim

Carbapenems

Cefepime

Colistin

Linezolid

Quinolone

Piperacillin/Tazobactam

Hospitalization in the same room with case

positive for $C$. difficile

GVHD

ERV

Co-infection

CMV

Parasites

Severe forms

Mortality within 14 days

General mortality

Neutropenia

Days of hospitalization. until diarrhea,

mean (variation)

Days of diarrhea until toxin collection

(variation)

Toxin collection until initiation of treatment

(variation)

Megacolon

Severe forms

\begin{tabular}{|c|c|}
\hline 3 & 4 \\
\hline 8 & 12 \\
\hline 30 & 44 \\
\hline 4 & 6 \\
\hline 9 & 13 \\
\hline 5 & 7 \\
\hline 7 & 10 \\
\hline 23 & 33 \\
\hline 46 & 67 \\
\hline 31 & 45 \\
\hline 4 & 6 \\
\hline 14 & 20 \\
\hline \multicolumn{2}{|c|}{ Mean 11 (1-407) } \\
\hline Mean $9(1$ & \\
\hline \multicolumn{2}{|c|}{ Mean $13(3-36)$} \\
\hline 61 & 88 \\
\hline 20 & 29 \\
\hline 37 & 54 \\
\hline 18 & 26 \\
\hline 13 & 19 \\
\hline 7 & 10 \\
\hline 9 & 13 \\
\hline 16 & 23 \\
\hline 18 & 26 \\
\hline 17 & 25 \\
\hline 30 & 44 \\
\hline 14 & 20 \\
\hline 3 & 5 \\
\hline 9 & 13 \\
\hline 19 & 26 \\
\hline 24 & 35 \\
\hline 32 & 46 \\
\hline
\end{tabular}

\section{TREATMENT}

Metronidazole IV

Metronidazole PO

Vancomycin IV

Vancomycin PO

Partial Response

End of treatment

Relapse

Patients did not finish treatment

GVHD: Graft versus host disease; VRE: Vancomycin-resistant enterococci, CMV cytomegalovirus; ATB: antibiotic. *number of patients with partial response in the first 7 days of treatment, number of patients who finished treatment and experienced symptom resolution, IV: intravenous; PO: oral the disease was found in only nine patients (14\%), and all of them died; seven of them $(80 \%)$ died within 14 days.

The bivariate analysis of the risk factors associated with the severe form of CDAD identified allogeneic HSCT, use of glycopeptides and cyclophosphamide as risk factors; however, the multivariate analysis did not identify any independent risk factor (Table 2).

The bivariate analysis of risk factors associated with death within 14 days of the diagnosis of CDAD identified allogeneic transplant, severe form of the disease, linezolid and cyclophosphamide use and hospitalization as risk factors for death and lymphoma as protector. Two models of multivariate analysis were conducted to evaluate the death outcome, one with and the other without the age variable. In spite of not showing $p<0.1$, age was included in the model because it had been described in various studies as a risk factor associated with mortality. On the other hand, ICU stay is a collinear variable of severity and was not included in the model (Table 3 ).

\section{DISCUSSION}

During the period studied, the cumulative incidence of CDAD was $3.1 \%$, it rose without increasing in clinical suspicion and severe forms of diseases. These data are interesting and in accordance with many countries that have been showing the increasing in CDAD incidence. Different denominators have been used to calculate the incidence of infection by $C$. difficile $e^{1,2,3,4,10,16,25}$. The guideline of CDAD recommends the using as denominator 100 thousand patients ${ }^{11}$. In our study, we opted to use two denominators, namely, patient-days and days of neutropenia, because of the population studied. The presence and duration of the neutropenia are important risk factors for healthcare associated infections in this population of patients, and has been used as a denominator by other authors ${ }^{14,17}$. One limitation of our study is precisely the method "ELISA" used to diagnosis infection by $C$. difficile that is not very sensitive, sensitivity varying from 63 to $94 \%{ }^{11}$.

We identified more CDAD in HSCT patients (69\%), of which $31 / 46$ $(67 \%)$ were allogeneic transplants, than in hematologic patients $(31 \%)$. The mean of days of HSCT until the onset of diarrhea was 11 days in the present study. TOMBLYN et al. $2002^{23}$ described a mean of one day after HSCT (varied from three to seven days). A greater frequency of C. difficile infection is expected during the first month after HSCT, a period when the patients are exposed to chemotherapy and antibiotics, important risk factors associated with this agent. Nine of sixty-four $(13 \%)$ patients presented the severe form of CDAD, higher than the 5\% previously described by WILLENS et al. $2012^{27}$.

Previous use of antimicrobials is cited by various authors ${ }^{1,2,4}$ as an important risk factor for the development of CDAD. Most of the patients of this study received antibiotics before the onset of the diarrhea; the most commonly used was carbapenem. However, $12 \%$ did not; this finding may be a result of crossover transmission of the agent, or exposure to other risk factors.

New drugs to treat CDAD are now available ${ }^{18}$, despite this, data have been showing that metronidazole is a safe option to treat $C$. difficile infection in hematologic and HCST patients, with few cases of relapse $\mathrm{e}^{13,16,27}$. In our study $57 \%$ of patients had symptoms ending with 


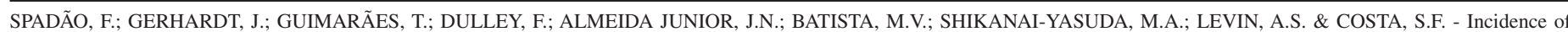
diarrhea by Clostridium difficile in hematologic patients and hematopoietic stem cell transplantation patients: risk factors for severe forms and death. Rev. Inst. Med. Trop. Sao Paulo, 56(4): 325-31, 2014

Table 2

Risk factors associated with the severe form of diarrhea caused by $C$. difficile in hematologic and HSCT patients

\begin{tabular}{|c|c|c|c|c|}
\hline \multirow[b]{2}{*}{ Variable } & \multicolumn{2}{|c|}{ Severe form } & \multicolumn{2}{|c|}{ Bivariate analysis } \\
\hline & $\begin{array}{c}\text { Yes } \\
\mathrm{N}=9\end{array}$ & $\begin{array}{c}\text { No } \\
\mathrm{N}=57\end{array}$ & OR $(95 \% \mathrm{CI})$ & $p$ value* \\
\hline Age & $21-57(39)$ & & & 0.5 \\
\hline Male & $5(11 \%)$ & $39(89 \%)$ & $0.6(0.15-3.1)$ & 0.41 \\
\hline \multicolumn{5}{|l|}{ Underlying disease } \\
\hline Lymphoma & $0(0)$ & $9(100 \%)$ & 0 & 0.26 \\
\hline AML & $4(13 \%)$ & $26(87 \%)$ & $1(0.22-4.5)$ & 0.61 \\
\hline ALL & $2(25 \%)$ & $6(75 \%)$ & $2.5(0.3-14.9)$ & 0.27 \\
\hline BML & $1(33 \%)$ & $3(67 \%)$ & 0 & 0.43 \\
\hline Medullary aplasia & $0(0)$ & $3(100 \%)$ & $2.3(0-24.8)$ & 0.65 \\
\hline Multiple myeloma & $0(0)$ & $5(100 \%)$ & 0 & 0.48 \\
\hline Allogeneic HSCT & $7(23 \%)$ & $24(77 \%)$ & 5.1(1-38.6) & $\mathbf{0 . 0 3}$ \\
\hline Autologous HSCT & $0(0)$ & $14(100 \%)$ & 0 & 0.11 \\
\hline \multicolumn{5}{|l|}{ Prior use } \\
\hline Quinolone & $2(22 \%)$ & $7(78 \%)$ & $2.1(0.25-12.1)$ & 0.33 \\
\hline Sulfamethoxole +trimethoprim & $1(5 \%)$ & $19(95 \%)$ & $0.27(0.01-1.88)$ & 0.19 \\
\hline Cefepime & $1(6 \%)$ & $17(94 \%)$ & $0.32(0.01-2.22)$ & 0.25 \\
\hline Carbapenems & $4(11 \%)$ & $33(89 \%)$ & $0.65(0.14-2.84)$ & 0.4 \\
\hline Colistin & $1(8 \%)$ & $12(92 \%)$ & $0.5(0.02-3.61)$ & 0.45 \\
\hline Glycopeptides & $2(5 \%)$ & $35(95 \%)$ & $0.2(0.02-1.02)$ & 0.04 \\
\hline Piperacillin-Tazobactam & $2(12 \%)$ & $14(88 \%)$ & $0.9(0.12-4.8)$ & 0.65 \\
\hline VRE & $2(7 \%)$ & $28(93 \%)$ & $0.3(0.04-1.62)$ & 0.15 \\
\hline CMV & $2(14 \%)$ & $12(88 \%)$ & $1.1(0.14-5.93)$ & 0.58 \\
\hline GVHD & $3(18 \%)$ & $14(82 \%)$ & $1.6(0.29-7.46)$ & 0.38 \\
\hline Days hospitalized for diarrhea, mean(variation) & $1(1-22)$ & $10(1-105)$ & & 0.16 \\
\hline Days for diarrhea collection toxins, mean & $1(1-20)$ & $1(1-18)$ & & 0.23 \\
\hline Collection of toxins/onset of treatment, mean & $2(1-6)$ & $1(0-20)$ & & 0.94 \\
\hline Chemotherapy & $2(6 \%)$ & $30(94 \%)$ & $0.29(0.03-1.42)$ & 0.11 \\
\hline Cyclophosphamide & $4(31 \%)$ & $9(69 \%)$ & 4.3(0.89-20.85) & 0.05 \\
\hline Steroids & $2(29 \%)$ & $5(71 \%)$ & $3(0.35-19.13)$ & 0.22 \\
\hline Immunosuppression & $7(15 \%)$ & $41(85 \%)$ & $1.6(0.32-12.24)$ & 0.44 \\
\hline Same room as a positive case for $C$. difficile & $0(0)$ & $18(100 \%)$ & 0 & 0.05 \\
\hline
\end{tabular}

GVHD: Graft versus host disease; AML: Acute Myeloid Leukemia, ALL; Acute Lymphoid Leukemia, CML: Chronic Myeloid Leukemia; HSCT VRE: Vancomycinresistant Enterococci; CMV: cytomegalovirus.

14 days of treatment. Coinfection and the presence o GVHD may be the reasons for the non-resolution of symptoms. The literature shows that, until the moment, there is a lack of association of resistance to metronidazole with non-response or relapse $e^{5,6,18,19,22,26}$. In Brazil, two studies that evaluated $C$. difficile susceptibility to metronidazole showed that all strains were susceptible to metronidazole and did not identified ribotype 027 in the country ${ }^{8,9}$. In the present study, it was not possible to evaluate the impact of sensitivity of $C$. difficile isolates on therapeutic response.

Quinolone is frequently used as bacterial prophylaxis during periods of neutropenia; it has been recently associated with outbreaks of community infection and severe form of $\mathrm{CDAD}^{4,11}$. Therefore, we assessed the association of previous use of quinolone with severe forms of disease. However, bivariate analysis showed that the risk factors for the severe form of CDAD were allogeneic HSCT, and use of glycopeptides and cyclophosphamide, risk factors directly associated with the severity of the patient. Sharing the same room was a protective factor for the development of the severe form of CDAD. Nevertheless, in the multivariate analysis it was not possible to identify any independent risk factor associated with the severe form of CDAD, probably due to the size of the population evaluated.

The mortality in the present study was not greater than previously described $^{1,10}$. Overall mortality was $37.5 \%, 34 \%$ in hematologic and $66 \%$ in HSCT patients, $58 \%$ of them allogeneic transplanted, and death within 


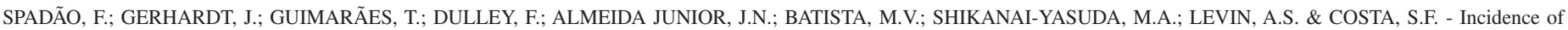
diarrhea by Clostridium difficile in hematologic patients and hematopoietic stem cell transplantation patients: risk factors for severe forms and death. Rev. Inst. Med. Trop. Sao Paulo, 56(4): 325-31, 2014

Tabela 3

Multivariate analysis of risk factors associated with the severe form of diarrhea caused by $C$. difficile in hematologic and HSCT patients

\begin{tabular}{lcc}
\hline \multirow{2}{*}{ Variable } & \multicolumn{2}{c}{ Multivariate analysis } \\
\cline { 2 - 3 } & OR $(95 \% \mathrm{CI})$ & $p$ value** \\
\hline Allogeneic HSCT & $2.5(0.2-23.9)$ & 0.40 \\
Glycopeptides & $0.25(0.03-1.7)$ & 0.16 \\
Cyclophosphamide & $4.9(0.5-43)$ & 0.14 \\
Same room as a posi- & $0(0-1.0)$ & 0.97 \\
tive case for $C$. difficile & & \\
\hline
\end{tabular}

GVHD: Graft versus host disease; AML: Acute Myeloid Leukemia, ALL; Acute Lymphoid Leukemia, CML: Chronic Myeloid Leukemia; HSCT VRE: Vancomycin-resistant Enterococci; CMV: cytomegalovirus.
14 days was 19/64 (26\%). On the other hand, the mortality among the severe form of CDAD was unusually high, $80 \%$ of patients died within 14 days. The severe forms of CDAD were treated with metronidazole in our study what can have been impacted in the high mortality. The IDSA guideline recommends the use of vancomycin orally for severe forms of $\mathrm{CDAD}$, but this presentation is not yet available in Brazil ${ }^{11}$.

Age is one of the primary risk factors associated with death in patients with CDAD ${ }^{20}$. The mean age of the patients studied in our cases was 38.9 years old, a young population probably due to the type of patient evaluated, $75 \%$ of patients of less than 50 years old and three $(5 \%)$ patients of 12 years old. Other risk factors described as associated with death in hematologic patients are colonization by VRE ${ }^{28}, \mathrm{GVHD}^{12}$ and severe form of diseases ${ }^{15,16}$. We found that the severe form of diseases, ICU stay, allogeneic HSCT, and use of cyclophosphamide and linezolid were risk factors for death within 14 days, and lymphoma was protector.

Table 4

Bivariate analysis of risk factors associated with death within 14 days of diagnosis of diarrhea by $C$. difficile in hematologic and HSCT patients

\begin{tabular}{|c|c|c|c|c|}
\hline \multirow{2}{*}{ Variable } & \multirow{2}{*}{$\begin{array}{c}\text { Death in } 14 \text { days } \\
\quad N=19\end{array}$} & \multirow{2}{*}{$\begin{array}{c}\text { Survival } \\
N=45\end{array}$} & \multicolumn{2}{|c|}{ Bivariate Analysis } \\
\hline & & & OR $(95 \% \mathrm{CI})$ & $p$ value \\
\hline Age, mean years old & $39(19-59)$ & $38(12-65)$ & & 0.76 \\
\hline \multicolumn{5}{|l|}{ Gender } \\
\hline Male & $13(29 \%)$ & $31(71 \%)$ & $1.3(0.43-4.35)$ & 0.41 \\
\hline \multicolumn{5}{|l|}{ Underlying disease } \\
\hline Lymphoma & $\mathbf{0}(\mathbf{0})$ & $9(100 \%)$ & $\mathbf{0}$ & 0.04 \\
\hline AML & $9(30 \%)$ & $21(70 \%)$ & $1.2(0.41-3.66)$ & 0.44 \\
\hline ALL & $3(37 \%)$ & $5(63 \%)$ & $1.6(0.29-8)$ & 0.38 \\
\hline CML & $0(0)$ & $4(100 \%)$ & 0 & 0.26 \\
\hline Medullary aplasia & $1(33 \%)$ & $2(67 \%)$ & $1.3(0-18.36)$ & 0.62 \\
\hline Multiple myeloma & $1(20 \%)$ & $4(80 \%)$ & $0.6(0.02-5.52)$ & 0.57 \\
\hline Allogeneic HSCT & $12(39 \%)$ & $19(61 \%)$ & $2.7(0.92-8.67)$ & 0.05 \\
\hline Autologous HSCT & $2(14 \%)$ & $12(86 \%)$ & $0.3(0.05-1.7)$ & 0.18 \\
\hline \multicolumn{5}{|l|}{ Prior use antibiotic } \\
\hline Quinolone & $3(38 \%)$ & $5(62 \%)$ & $0.5(0.11-3.42)$ & 0.26 \\
\hline Sulfa+trimethoprim & $7(35 \%)$ & $13(65 \%)$ & $1.6(0.51-5.15)$ & 0.27 \\
\hline Cefepime & $5(28 \%)$ & $13(72 \%)$ & $1(0.3-3.37)$ & 0.60 \\
\hline Carbapenem & $13(35 \%)$ & $24(65 \%)$ & $2.3(0.76-7.15)$ & 0.10 \\
\hline Colistin & $6(46 \%)$ & $7(54 \%)$ & $2.8(0.8-9.94)$ & 0.09 \\
\hline Glycopeptides & $10(27 \%)$ & $27(73 \%)$ & $0.9(0.32-2.72)$ & 0.56 \\
\hline Linezolid & $4(57 \%)$ & $3(43 \%)$ & $4.1(0.83-20.8)$ & 0.08 \\
\hline Piperacillin/Tazobactam & $3(19 \%)$ & $13(81)$ & $0.5(0.13-2.13)$ & 0.28 \\
\hline Febrile neutropenia & $7(22 \%)$ & $25(78 \%)$ & $0.5(0.18-1.74)$ & 0.24 \\
\hline CMV & $4(29 \%)$ & $10(71 \%)$ & $1(0.25-3.89)$ & 0.58 \\
\hline VRE & $6(20 \%)$ & $24(80 \%)$ & $0.5(0.15-1.53)$ & 0.16 \\
\hline Other parasites & $0(0)$ & $5(100 \%)$ & 0 & 0.18 \\
\hline Severe form & $7(79 \%)$ & $2(22 \%)$ & $13.2(2.6-103.59)$ & 0.001 \\
\hline Immunosuppressor & $16(33 \%)$ & $32(67 \%)$ & $2.9(0.8-14.22)$ & 0.08 \\
\hline Chemotherapy & $7(22 \%)$ & $25(78 \%)$ & $0.5(0.18-1.74)$ & 0.24 \\
\hline Steroids & $3(43 \%)$ & $4(57 \%)$ & $2.1(0.36-11.39)$ & 0.29 \\
\hline Cyclophosphamide & $6(46 \%)$ & $7(54 \%)$ & $3(0.83-11.37)$ & 0.09 \\
\hline ICU stay & $11(52 \%)$ & $10(48 \%)$ & $5.3(1.69-17.63)$ & 0.003 \\
\hline
\end{tabular}

AML: Acute Myeloid Leukemia; ALL: Acute Lymphoid Leukemia; CML: Chronic Myeloid Leukemia; HSCT: hematopoietic stem cells transplant; VRE: Vancomycinresistant enterococci; CMV: cytomegalovirus; ICU: Intensive Care Unit. 


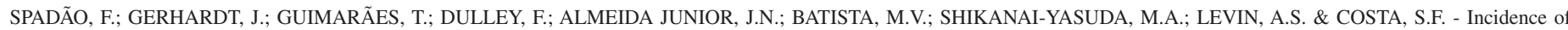
diarrhea by Clostridium difficile in hematologic patients and hematopoietic stem cell transplantation patients: risk factors for severe forms and death. Rev. Inst. Med. Trop. Sao Paulo, 56(4): 325-31, 2014

Table 5

Mutivariate analysis of risk factors associated with death within 14 days of diagnosis of diarrhea by $C$. difficile in hematologic and HSCT patients

\begin{tabular}{lcc}
\hline \multirow{2}{*}{ Variable } & \multicolumn{2}{c}{ Multivariate Analysis } \\
\cline { 2 - 3 } & OR $(95 \% \mathrm{CI})$ & $p$ value \\
\hline Lymphoma & $0(0.0-1.0)$ & 0.96 \\
Allogeneic HSCT & $2.14(0.65-7.21)$ & 0.22 \\
Linezolid & $\mathbf{5 . 0 2}(\mathbf{1 - 2 5 . 0})$ & $\mathbf{0 . 0 5 0}$ \\
Severe form & $\mathbf{8 . 9 0}(\mathbf{1 . 9 2 - 4 1 . 0})$ & $\mathbf{0 . 0 1 5}$ \\
Cyclophosphamide & $2.513(0.61-10.0)$ & 0.19 \\
\hline
\end{tabular}

No patient with lymphoma died. In the multivariate analysis, however, the variables that remained as independent risk factors for death were severe form of the disease, and the use of linezolid. The risk factors identified in the present study are merely a marker of severity. VRE has been previously described as risk factor for CDAD; however, it was not identified as risk factor in our study. On the other hand, linezolid that has been used in our hospital to treat patients colonized by VRE, with persistent febrile neutropenia, or in sepsis and septic shock was a risk factor, unlike two previous studies that showed a potential benefit of linezolid in CDAD, an "in vitro" study that showed action of linezolid against $C$. difficile using a gut model and a epidemiologic study that demonstrated that linezolid protected patients with ventilator-associated pneumonia to develop $\mathrm{CDAD}^{7,24}$.

\section{CONCLUSIONS}

The incidence of CDAD increased significantly over the study period; however, the severe form of diseases remained stable. The independent risk factors associated with death in hematologic and HSCT patients in 14-days of onset of CDAD were severe form of the disease, and the use of linezolid.

\section{RESUMO}

\section{Diarreia por Clostridium difficile em pacientes hematológicos e transplantados de células tronco hematopoiéticas: fatores de risco da forma grave e morte}

Descrevemos a taxa de incidência de diarreia associada a Clostridium difficile (CDAD) em pacientes hematológicos e submetidos a transplante de células-tronco hematopoiéticas (TCTH) internados no HC-FMUSP no período de janeiro de 2007 a junho de 2011 usando dois denominadores 1.000 paciente e 1.000 dias de neutropenia e os fatores de risco associados à forma grave da doença e morte. O método de ELISA (RidascreenBiopharm, Germany) de detecção de toxinas A/B foi utilizado para o diagnóstico de $C$. difficile. Análise multivariada usando regressão logística múltipla foi conduzida para avaliar os potenciais fatores de risco associados com forma grave de CDAD e morte em até 14 dias do diagnóstico. Sessenta e seis episódios foram identificados em 64 pacientes entre 439 pacientes que apresentaram diarreia durante o período do estudo. A taxa de incidência de CDAD variou de 0,78 a 5,45 por 1.000 dias de neutropenia e de 0,65 para 5,45 por 1.000 pacientes-dias. A doença de base mais comum foi leucemia mielóide aguda 30/64(44\%), 32/64
(46\%) pacientes estavam neutropênicos, 31/64 (45\%) foram submetidos à TCTH alogênico, 61/64 (88\%) usaram antibióticos previamente e 9/64 $(13 \%)$ apresentaram forma grave da doença. A maioria dos pacientes (89\%) utilizou metronidazol oral no tratamento da CDAD e 19/64 (26\%) evoluiram para óbito. Os fatores de risco independentes associados à morte foram forma grave da doença e uso de linezolida.

\section{ACKNOWLEDGMENTS SECTION}

There is no conflict of interest. This study had no financial funding.

\section{REFERENCES}

1. Alonso CD, Treadway SB, Hanna DB, Huff CA, Neofytos D, Carroll KC, et al. Epidemiology and outcomes of Clostridium difficile infections in hematopoietic stem cell transplant recipients. Clin Infect Dis. 2012;54:1053-63.

2. Altclas J, Requejo A, Jaimovich G, Milovic V, Feldman L. Clostridium difficile infection in patients with neutropenia. Clin Infect Dis. 2001;5:723.

3. Arango JI, Restrepo A, Schneider DL, Callander NS, Ochoa-Bayona JL, Restrepo MI, et al. Incidence of Clostridium difficile associated diarrhea before and after autologous peripheral blood stem cell transplantation for lymphoma and multiple myeloma. Bone Marrow Transplant. 2006;37:517-21.

4. Avery R, Pohlman B, Adal K, Bolwell B, Goldman M, Kalaycio M, et al. High prevalence of diarrhea but infrequency of documented Clostridium difficile in autologous peripheral blood progenitor cell transplant recipients. Bone Marrow Transplant. 2000;25:67-9.

5. Arvand M, Hauri AM, Zaiss NH, Witte W, Bettge-Weller G. Clostridium difficile ribotypes 001, 017 and 027 are associated with lethal C. difficile infection in Hesse, Germany. Euro Surveill. 2009;14(45):pii=19403.

6. Bacci S, Molback K, Kjeldsen MK, Olsen KEP. Binary toxin and death after Clostridium difficile infection. Emerging Infect Dis. 2011;17:976-82.

7. Baines SD, Noel AR, Huscroft GS, Todhunter SL, O'Connor R, Hobbs JK, et al. Evaluation of linezolid for the treatment of Clostridium difficile infection caused by epidemic strains using an in vitro human gut model. J Antimicrob Chemother. 2011;7:1537-46.

8. Balassiano IT, Miranda KR, Boente RF, Pauer H, Oliveira IC, Santos-Filho J, et al. Characterization of Clostridium difficile strains isolated from immunosuppressed inpatients in a hospital in Rio de Janeiro, Brazil. Anaerobe. 2009;15:61-4.

9. Balassiano IT, dos Santos-Filho J, Vital-Brazil JM, Nouér SA, Souza CR, Brazier JS, $e$ al. Detection of cross-infection associated to a Brazilian PCR-ribotype of Clostridium difficile in a university hospital in Rio de Janeiro, Brazil. Antonie Van Leeuwenhoek. 2011;99:249-55.

10. Bilgrami S, Feingold JM, Dorsky D, Edwards RL, Bona RD, Khan AM, et al. Incidence and outcome of Clostridium difficile infection following autologous peripheral blood stem cell transplantation. Bone Marrow Transplant. 1999;23:1039-42.

11. Cohen SH, Gerding DN, Johnson S, Kelly CP, Loo VG, McDonald LC, et al. Clinical practice guidelines for Clostridium difficile infection in adults: 2010 update by the society for healthcare epidemiology of America (SHEA) and the infectious diseases society of America (IDSA). Infect Control Hosp Epidemiol. 2010;31:431-55.

12. Chakrabarti S, Lees A, Jones SG, Milligan DW. Clostridium difficile infection in allogeneic stem cell transplant recipients is associated with severe graft-versus-host disease and non-relapse mortality. Bone Marrow Transplant. 2000;26:871-6.

13. Chopra T, Chandrasekar P, Salimnia H, Heilbrun LK, Smith D, Alangaden GJ. Recent epidemiology of Clostridium difficile infection during hematopoietic stem cell transplantation. Clin Transplant. 2011;25:82-7. 


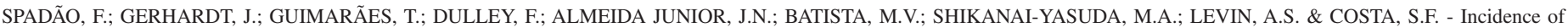

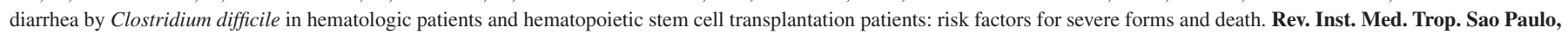
56(4): 325-31, 2014.

14. Dettenkofer M, Wenzler-Röttele S, Babikir R, Bertz H, Ebner W, Meyer E, et al. Surveillance of nosocomial sepsis and pneumonia in patients with a bone marrow or peripheral blood stem cell transplant: a multicenter project. Clin Infect Dis. 2005;40:926-31.

15. Dubberke ER, Sadhu J, Gatti R, Reske KA, DiPersio JF, Devine SM, et al. Severity of Clostridium difficile-associated disease (CDAD) in allogeneic stem cell transplant recipients: evaluation of a CDAD severity grading system. Infect Control Hosp Epidemiol. 2007;28:208-11

16. Leung S, Metzger BS, Currie BP. Incidence of Clostridium difficile infection in patients with acute leukemia and lymphoma after allogeneic hematopoietic stem cell transplantation. Infect Control Hosp Epidemiol. 2010;31:313-5.

17. Mendes ET, Dulley F, Basso M, Batista MV, Coracin F, Guimarães T, et al. Healthcareassociated infection in hematopoietic stem cell transplantation patients: risk factors and impact on outcome. Int J Infect Dis. 2012;16:424-8.

18. Musgrave CR, Bookstaver PB, Sutton SS, Miller AD. Use of alternative or adjuvant pharmacologic treatment strategies in the prevention and treatment of Clostridium difficile infection. Int J Infect Dis. 2011;15:438-48.

19. Oka K, Osaki T, Hanawa T, Kurata S, Okazaki M, Manzoku T, et al. Molecular and microbiological characterization of Clostridium difficile isolates from single, relapse, and reinfection cases. J Clin Microbiol. 2012;3:915-21.

20. Ram R, Gafter-Gvili A, Raanani P, Yeshurun M, Shpilberg O, Dreyer J, et al. Surveillance of infectious complications in hemato-oncological patients. Isr Med Assoc J. 2009;3:133-7

21. Schalk E, Bohr UR, Konig B, Scheinpflug K, Mohren M. Clostridium difficile-associated diarrhoea, a frequent complication in patients with acute myeloid leukaemia. Ann Hematol. 2010;89:9-14.
22. Tenover FC, Tickler IA, Persing DH. Antimicrobial-resistant strains of Clostridium difficile from North America. Antimicrob Agents Chemother. 2012;56:2929-32.

23. Tomblyn M, Gordon L, Singhal S, Tallman M, Williams S, Winter J, et al. Rarity of toxigenic Clostridium difficile infections after hematopoietic stem cell transplantation: implications for symptomatic management of diarrhea. Bone Marrow Transplant 2002;30:517-9

24. Valerio M, Pedromingo M, Muñoz P, Alcalá L, Marin M, Peláez T, et al. Potential protective role of linezolid against Clostridium difficile infection. Int J Antimicrob Agents. 2012;5:414-9.

25. Vehreschild MJ, Meissner AM, Cornely OA, Maschmeyer G, Neumann S, von Lilienfeld Toal M, et al. Clinically defined chemotherapy-associated bowel syndrome predicts severe complications and death in cancer patients. Haematologica. 2011;96:1855-60.

26. Venugopal AA, Riederer K, Patel SM, Szpunar S, Jahamy H, Valenti S, et al. Lack of association of outcomes with treatment duration and microbiologic susceptibility data in Clostridium difficile infections in a non-NAP1/BI/027 setting. Scand J Infect Dis. 2012;44:243-9.

27. Willems L, Porcher R, Lafaurie M, Casin I, Robin M, Xhaard A, et al. Clostridium difficile infection after allogeneic hematopoietic stem cell transplantation: incidence, risk factors, and outcome. Biol Blood Marrow Transplant. 2012;18:1295-301.

28. Zirakzadeh A, Gastineau DA, Mandrekar JN, Burke JP, Johnston PB, Patel R Vancomycin-resistant enterococcal colonization appears associated with increased mortality among allogeneic hematopoietic stem cell transplant recipients. Bone Marrow Transplant. 2008;41:385-92.

Received: 18 April 2013

Accepted: 7 January 2014 